\title{
Illiquidity, duration and momentum profits: evidence from the Korean stock market
}

\author{
Jaewan Bae \\ Korea Advanced Institute of Science and Technology Business School, \\ Seoul, Republic of Korea, and \\ Changjun Lee \\ College of Business, Hankuk University of Foreign Studies, \\ Seoul, Republic of Korea \\ Seoul, Ret
}

Korean stock market

\begin{abstract}
This paper examines the role of illiquidity and duration factor in understanding the momentum profit in the Korean stock market. We find that the foreigner/institutional illiquidity factor explains the momentum effect. In addition, this paper finds that duration factor defined as the difference in returns of short-duration and longduration stocks captures well the momentum profits. That is, a two-factor model with the market and duration factor performs much better than competing asset pricing models in explaining the momentum effect. Finally, when controlling for the duration factor, the explanatory power of the foreign/institutional illiquidity factor on the momentum profits disappears. In sum, our empirical finding indicates that the duration factor is the most important ingredient in understanding the momentum effect in the Korean stock market.
\end{abstract}

Keywords Duration, Market liquidity, Momentum effect, Duration factor, Illiquidity factor

Paper type Research paper

\section{Introduction}

The momentum effect, relatively high-performance stocks in the past 6-12 months continue to outperform in the next 6-12 months, is one of the most puzzling phenomena in finance. Since Jegadeesh and Titman's (1993) pioneering work for the US stock market, it has been observed in other countries (Rouwenhorst, 1998; Griffin et al., 2003; Fama and French, 2012) and not explained by the existing asset pricing models such as the Fama-French three-factor model. Moreover, recent papers including the work of Asness et al. (2013) document that the momentum effect does exist in the bond market, commodity future market and currency market as well. With these facts, in the US stock market, numerous researchers have studied whether the momentum effect truly exists or not and driving forces behind the momentum effect.

(C) Jaewan Bae and Changjun Lee. Published in Journal of Derivatives and Quantitative Studies: 선물연구. Published by Emerald Publishing Limited. This article is published under the Creative Commons Attribution (CC BY 4.0) licence. Anyone may reproduce, distribute, translate and create derivative works of this article (for both commercial and non-commercial purposes), subject to full attribution to the original publication and authors. The full terms of this licence maybe seen at http://creativecommons.org/licences/by/4.0/legalcode

JEL classification - G11, G12, G14

This work was supported by IREC, The Institute of Finance and Banking and Seoul National University. Changjun Lee is grateful for the Hankuk University of Foreign Studies Research Fund.

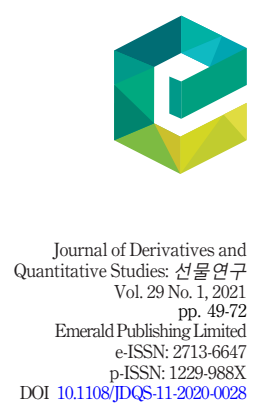


JDQS 29,1

On the contrary, few studies have been conducted in the Korean stock market regarding momentum effect, and most works have focused whether the momentum effect is present in the Korean stock market. It is because most of the early works in Korea fail to find the momentum effect (Jung and Kim, 2002; Ahn and Lee, 2004; Kho, 2006). However, recent studies using post-Asian financial crisis period data discover the existence of the momentum effect in the Korean stock market (Eom, 2013; Lee and Jang, 2015; Jang, 2017; Kim and Lee, 2018), and there is now a consensus on the existence of the momentum effect in the Korean stock market during the post-Asian financial crisis period.

Given that, this study attempts to understand the driving force behind the momentum effect. Specifically, based on prior research in overseas and the Korean markets, we examine an explanatory power of the illiquidity factor and the duration factor for returns of momentum strategy. The reasons we focus on the two factors are as follows. First, we use the illiquidity factor because prior studies report that the performance of the momentum strategy is positively related to market liquidity (Avramov et al., 2016; Kim and Lee, 2018). When the market liquidity increases, stocks with relatively low liquidity outperform stocks with high liquidity, and the illiquidity factor which is defined as the difference in the returns between low and high liquidity stocks is likely to earn positive returns. Therefore, if the momentum strategy shows a better performance when the market liquidity improves as with the results of prior research, the illiquidity factor should explain the performance of the momentum strategy. In addition, our study divides the illiquidity factor into the illiquidity factor of foreigners and institutions (named foreign/institutional illiquidity factor, IML_FI) and the illiquidity factor of individuals (named individual illiquidity factor, IML_ID). This is related to Kim and Lee (2018), who document that the momentum effect appears after the crisis when foreign investors have actively invested, and related to Kang et al. (2014), who report that the momentum profits of foreign investors after the crisis are linked to the existence of momentum effect in the Korean stock market.

Next, our study examines whether the stock-duration factor (hereafter duration factor if not confused) can explain the momentum profits for the following reasons. First, duration has traditionally been an important tool in bond markets, but more recently, a few studies have used duration to explain cross-sectional differences in stock returns (Lettau and Wachter, 2007; Chen and Yang, 2019; Moon and Song, 2019). In particular, Chen and Yang (2019) explain the time-series movement of momentum strategies using the fact that past winners have shorter durations than the past losers. Second, it is likely that the duration factor is related to the previously proposed illiquidity factor. If a change in time preference raises the preference for shorter duration stocks that provide more revenues in the shortterm future, the return on the duration factor is positively realized, and the momentum profit is also likely to be positively realized as winners with a relatively shorter duration are preferred. Moreover, an increase in the preference for shorter duration stocks accompanies an increase in the market liquidity, resulting in positive returns on the illiquidity factors. This mechanism could allow the illiquidity factors to explain returns on momentum strategy.

Our empirical findings are summarized of as follows. First, consistent with prior research, the momentum effect is observed in the Korean stock market after the crisis. We define WMLx as a portfolio that takes a long position on stocks of the highest $x \%$ past returns and a short position on stocks of the lowest $x \%$ past returns, and we examine the performance of three strategies: WML10, WML20 and WML30. As a result, the average monthly return on the three long-short portfolios are estimated at $0.50 \%-1.06 \%$ per month, and the CAPM, the Fama-French three-factor model (FF3, hereafter) and the Fama-French 
five-factor model (FF5, hereafter) fail to explain the momentum profits in the Korean stock market.

Second, we find that the IML_FI is able to explain the momentum effect. In our study, the

Korean stock market overall illiquidity factor is divided into IML_FI and IML_ID. According to the time-series regression in which monthly returns of the three momentum strategies are dependent variables, and IML_FI and IML_ID with the factors on existing asset pricing models (CAPM, the FF3 and the FF5) are independent variables, the estimated coefficient on IML_ID is -0.03 to -0.11 with absolute $t$-values less than one. In other words, the explanatory power of the IML_ID for the momentum effect barely exists in the Korean stock market. In a sharp contrast, the coefficient on IML_FI is estimated at $0.21-0.29$ which is relatively high compared to that of IML_ID. This suggests that the IML_FI is more important in understanding the momentum effect. In addition, the IML_FI helps to explain the momentum profits given that all the estimated coefficient for IML_FI are positive and the average return for IML_FI is $0.77 \%$ per month.

Third, in the Korean stock market, the duration factor defined as the difference between the realized return of short-term and long-term duration stocks earns a significantly positive premium which is not explained by the existing asset pricing models. The average monthly return on the equal- (value-) weighted $1-10$ portfolio is $2.85 \%(1.56 \%)$ per month, and it is statistically significant. Furthermore, the duration factor is not explained by the CAPM, the FF3 and the FF5. This implies that the duration factor is further exposed to a risk that is distinguished from existing factors, providing a risk premium. Spanning tests among factors also confirm that the duration factor has a statistically significant positive relationship with the IML_FI, which supports the hypothesis of our study that predicts a positive relationship between the two factors.

Fourth, we find that the duration factor comparably well captures the returns of the momentum strategy. In the time-series regression in which the monthly return of momentum strategies is a dependent variable and the monthly return of the market factor and duration factor are explanatory variables, every exposure of momentum strategy return on the duration factor (NMF) is statistically significant. In addition, we investigate the explanatory power of each individual asset pricing model for the momentum strategies. The model consisting of the market and duration factor shows an explanatory power of $54 \%$ $67 \%$, which is significantly higher than the FF3 with an explanatory power of $15 \%-35 \%$ or the FF5 with that of $18 \%-36 \%$. In particular, the risk-adjusted alpha is not statistically significant, and the market factor's beta is low and insignificant in all regressions, which indicates that most of the explanatory power of the model nesting the market and duration factor on the momentum strategy mainly stems from the duration factor.

Finally, when controlling for the duration factor, the explanatory power of the IML_FI on the momentum strategy returns disappears. In the time-series regression with returns of momentum strategy as a dependent variable and the market factor, duration factor, foreign/ institutional and IML_ID as independent variables, the estimated betas on the IML_FI for all momentum strategies are not statistically significant, and the magnitude of the betas is close to zero. In contrast, the slope of the duration factor is still significant and economically large. As a result, our empirical results support that the duration factor is the most important ingredient in understanding the performance of the momentum strategy in the Korean stock market.

Our study is different from prior works in that our study attempts to understand the driving forces behind the momentum effect, while most prior studies have only focused on the existence of the momentum effect. Of course, Kim and Lee (2018) investigate the relationship between the momentum effect and the market liquidity in the Korean stock 
JDQS 29,1

market. However, they focus on the pre-Asian financial crisis period, not the post-Asian financial crisis period, and attempt to explain why momentum effect does not exist in the Korean stock market during that period. Our study is also related to Moon and Song (2019), who document the explanatory power of duration for cross-sectional stock returns. Their work is related to ours in that duration is an important risk factor that is distinct from traditional factors, but our study differs from theirs in that we examine the relation between the duration factor and the illiquidity factor. More importantly, we study whether duration factor can explain the momentum effect in the Korean stock market.

We attempt to discover the driving forces behind the momentum effect, a newly discovered asset pricing anomaly in the Korean stock market. Given the fact that understanding the cross section of stock returns is one of the most fundamental and important questions in finance, our work contributes to the existing literature on empirical asset pricing. In particular, our study is meaningful considering the lack of papers studying on the source of momentum investment strategies in the Korean stock market.

This study is organized as follows. First, we review related literature in Section 2. We describe data and provide main variables in Section 3 and report empirical results in Section 4. In Section 5, we conclude.

\section{Literature review and implications}

Literature on the momentum effect can be largely classified as studies on the existence of the momentum effect and the driving forces behind the momentum effect. Research on the sources of the momentum effect has been actively carried out in the US stock market, but most of the research is limited to the existence of the momentum effect in the Korean stock market. In this section, we draw implications by reviewing related literature in overseas and the Korean markets.

\subsection{Literature review for the existence of momentum}

2.1.1 Overseas literature. Since the pioneering work of Jegadeesh and Titman (1993) in the US stock market, numerous researchers have studied on the momentum effect. First, researchers have examined whether momentum is observed in other countries' stock markets including the European stock markets, and they report that the momentum effect exists in other countries too. For example, using the stock market data in 12 European countries from 1980 to 1995, Rouwenhorst (1998) finds that even after controlling for several risk factors, the average monthly return on the momentum strategy is approximately $1 \%$ per month, indicating that the momentum effect is also present in the European markets. Recently, Fama and French (2012) divide the global stock market into North America, Europe, Japan and Asian markets excluding Japan and find that there is the momentum effect among the stock markets except Japan.

Second, prior works document that the momentum effect appears not only in stock markets but also in government bonds, currencies and commodity futures markets. Asness et al. (2013) examine the momentum effects in diverse asset markets such as the US, UK, Europe and Japan stock markets, and they find that momentum profit is present in bond, currency and commodity futures markets as well. Recently, Brooks et al. (2018) discover the presence of the momentum effect in the US corporate bond market.

Third, researchers have studied on the observing period for the performance of momentum strategy. To measure the performance of the momentum strategy, a period (J) for measuring past returns and a period for measuring future returns $(\mathrm{K})$ are required. Jegadeesh and Titman (1993) use the period for measuring past and future returns by 3, 6, 9 and 12 months, respectively. Then, they analyze the performance of the momentum strategy 
for a total of 16 combinations. Fama and French (1996) measure the performance of a momentum strategy by setting the period for measuring past returns by 11 months and the period for measuring future returns by one month. In addition, Novy-Marx (2012) finds that the performance of its momentum strategy is improved when a momentum portfolio is formed using returns between the past 12 and 7 months. In conclusion, the momentum effect has still been observed since its debut in 1993, and now the momentum profit is present in various asset classes.

2.1.2 Literature in the Korean stock market. Empirical evidence on the momentum effect

Korean stock market during the post-Asian financial crisis period is dramatically different from that during the pre-Asian financial crisis period. While earlier works studying pre-Asian financial crisis period report that momentum effect does not exist, recent studies using post-Asian financial crisis period data or relatively long-term data find the momentum effect in the Korean stock market. Prior studies are summarized as follows.

Earlier studies including Jung and Kim (2002) and Ahn and Lee (2004) document the reversal effect rather than the momentum effect in the Korean stock market. In addition, Kho (2006) also fails to find momentum effect in the Korean stock market using data from 2001 to 2004. However, recent studies using post-Asian financial crisis data find momentum effect in the Korean stock market. Eom (2013) examines stocks listed in Korea Composite Stock Price Index (KOSPI) and Korea Securities Dealers Automated Quotations (KOSDAQ) from 1980 to 2009 and reports that there is a negative momentum effect before the crisis, but the positive momentum effect exists after the crisis. He additionally shows that the momentum effect is stronger among firms with a high foreign ownership. Using the data from 1987 to 2014, Lee and Jang (2015) also report that the momentum effect has been strong in the Korean stock market since 2000. Furthermore, Kim and Lee (2018) confirm the existence of the momentum effect in the period after 2000, and they show that the momentum effect that has been evident in the Korean stock market since 2000 is related to the increase in market liquidity. In addition, Jang (2017) reports that the performance of the intermediate-term momentum strategy, which is formed using the past 12 to 7 month returns, outperforms the performance of the momentum strategy using the returns in the past six months, consistent with the findings of Novy-Marx (2012) in the US stock market.

\subsection{Literature review for the source of momentum}

2.2.1 Risk-based and behavioral explanations. While most prior studies in the Korean stock market have focused on the existence of the momentum effect, studies on the source of the momentum effect have been actively conducted in overseas markets. The momentum effect can be regarded as an anomaly in that it cannot be explained by the existing asset pricing models such as CAPM, the FF3 and the FF5. Thus, numerous researchers have attempted to understand the momentum effect based on risk-based and behavioral explanations [1].

First, studies on risk-based explanation can be summarized as follows. Analyzing the effect of the market liquidity on the expected returns, Pástor and Stambaugh (2003) find that a liquidity-based risk factor could account for approximately $50 \%$ of the momentum return in the US equity market. In addition, Bansal et al. (2005) report that consumption risk based on cash flows has a significant relation with the performance of the momentum strategy. In addition, Liu and Zhang (2008) find that past winners have a higher sensitivity to the industrial production growth rate than past losers, which can explain the momentum effect.

Second, studies on behavioral explanation can be summarized as follows. Daniel et al. (1998) argue that the momentum profit is manifested by investors' overconfidence and self-attributive bias. In addition, Barberis et al. (1998) and Hong and Stein (1999) report that investors' underreaction to information could cause the momentum effect. 
JDQS 29,1

Cooper et al. (2004) find that the performance of momentum strategy is related to the overall market state, especially the overall past returns on the stock market, and that their empirical results are consistent with the behavioral model. Finally, Chui et al. (2010) use the individualism index introduced by Hofstede (2001) to investigate the phenomenon that the presence of the momentum effect varies from country to country. They find that the existence of momentum effect is significantly related to the individualism index of countries, which also explain why researchers have failed to find the momentum effect in Asian countries where individualism is relatively weak.

While the aforementioned studies have shown some achievement, it is believed that there is no perfect model yet for the majority to agree on the momentum effect. For example, several papers have tried to explain the momentum effect with existing risk-based theory, but no satisfactory results have been presented. For example, with the FF3, the slopes on value factor (HML) of past winners are lower than those of past losers, meaning that the FF5 does not explain the momentum effect. In addition, the behavioral approach presented in individual studies has its own achievement, but there is an overall disagreement on interpreting the momentum effect as overreaction and underreactions, which are conflicting.

2.2.2 Other studies. Recent papers including Avramov et al. (2016) and Chen and Yang (2019) provide a new perspective on understanding the momentum effect. The work of Avramov et al. (2016) is different from prior studies as they show that the momentum effect is stronger when the market liquidity is high, unlike other anomalies. As Chordia et al. (2014) document, most anomalies in stock markets are stronger in the low market liquidity state, implying that they are linked to the limit-to-arbitrage. However, Avramov et al. (2016) empirically show that the momentum profit is positively related with market liquidity in the USA, Japan and the ten euro-zone countries.

The work of Chen and Yang (2019) is distinct from prior research in that it explains the time-series pattern of momentum returns considering different durations between past winners and past losers [2]. Their findings are summarized as follows. First, the duration of past winners (15.99) is lower than that of past losers (18.31) because past winners have a higher dividend growth rate than past losers. Second, citing Albuquerque et al. (2016) who shows that the risk of time value is also priced in the market, they argue that investors assign different values for the short-term future and long-term future over time because of longevity risk. For example, increasing life expectancy implies that investors will spend further into the future, which is in fact equivalent to a decline in current wealth, and which is perceived as a bad market state. At this time, relatively long-duration stocks can hedge this bad state caused by increasing life expectancy. Thus, investors would demand a low expected return on these stocks. Third, Chen and Yang (2019) use the longevity risk as a variable affecting time preference. That is, if investor's life expectancy is realized to be higher than expected (if time preference for the far future increases), they will try to increase future consumption and reduce current consumption. As a result, Chen and Yang (2019) empirically prove that as longevity risk changes over time, preferences for stocks with different durations also change, and it leads to time-varying momentum returns.

\subsection{Implications}

Reviewing the prior studies leads to important implications. First, the study of Avramov et al. (2016) and the fact that the momentum effect exists after the crisis when market liquidity has increased imply that liquidity can play an important role in understanding the momentum phenomenon in the Korean stock market. In particular, we examine how foreign and institutional investors contribute to the formation of the momentum effect from the perspective of the fact that the increase in liquidity in the Korean stock market is related to 
the expansion of participation of foreign and institutional investors. Second, we examine whether there is a significant relation between stock durations and momentum returns given that prior works have not investigated the relationship between the two in the Korean stock market.

\section{Data and methodology}

\subsection{Data}

We use common stocks listed on KOSPI and KOSDAQ from July 2001 to June 2019. Stocks with a negative book value are excluded from the analysis and stocks that have missing values of momentum, illiquidity, trading volume ratios by trader types and durations are also excluded. All of the stock market data and accounting data required for this analysis are obtained from FnGuide's database. Total returns including dividends are used as stock returns, and monthly CD 91 rates are used as a proxy for a risk-free rate.

\subsection{Main variables}

3.2.1 Momentum. Novy-Marx (2012) shows a superior performance in the intermediate-term momentum strategy which is formed using returns in the past 12 to 7 months, compared to forming a momentum portfolio using returns in the past six months. In the Korean stock market, Jang (2017) finds empirical results consistent with findings of Novy-Marx. Guided by these studies, we also measure the past returns as the sum of the monthly returns from the end of the month $t-11$ to the end of the month $t-6$ as of the end of each month $t$ (formation period).

3.2.2 Illiquidity. Following Avramov et al. (2016), we use the illiquidity measure introduced by Amihud (2002). The illiquidity of stock $i$ is calculated at monthly frequency using daily stock market data for the past six months as follows:

$$
I L L I Q_{i, t}=\frac{1}{D_{i, t}} \sum_{d=1}^{D_{i, t}} \frac{\left|R_{i, d}\right|}{V O L_{i, d}}
$$

$R_{i, d}$ is return, and $V O L_{i, d}$ is trading volume on day $d$, respectively, and $D_{i, t}$ is the number of days with nonzero trading volume. We include stocks that have at least 50 available daily observations for the past six months.

3.2.3 Trading ratio of foreign and institutional investors. To measure which group has led more transactions for individual stocks, we use the sum of foreign and institutional trading volume and individual trading volume. Specifically, at the end of each month $t$, the sum of the foreign and institutional trading volume divided by the total trading volume (the sum of the foreign, institutional and individual trading volume) for stock $i$ is defined as the trading ratio for foreigners and institutions, which is denoted as $\mathrm{FIR}_{\mathrm{i}, \mathrm{t}}$. We define $V_{\text {o }}{ }_{i, t} \mathrm{~F}$. and $V o l_{i, t}^{I D}$ as the trading volume of foreigners/institutions (FI) and individuals (ID) for stock $i$ over the past six months as of time $t$, respectively. Then, $\mathrm{FIR}_{\mathrm{i}, \mathrm{t}}$ is defined by equation (2):

$$
\mathrm{FIR}_{\mathrm{i}, \mathrm{t}}=\operatorname{Vol}_{i, t}^{F I} /\left(\operatorname{Vol}_{i, t}^{F I}+\operatorname{Vol}_{i, t}^{I D}\right)
$$

3.2.4 Duration. To estimate duration of individual stocks, we follow the methodology of Weber (2018), who calculates cash flow duration based on Macaulay duration. The definition of cash flow duration is given in equation (3) as follows: 
JDQS 29,1

$$
D U R=\frac{\Sigma_{t=1}^{T} t * C F_{t} /(1+r)^{t}}{M E}+\left(T+\frac{1+r}{r}\right) * \frac{\Sigma_{s=T+1}^{\infty} t * C F_{s} /(1+r)^{s}}{M E}
$$

In equation (3), $\mathrm{ME}$ is the market value at the time of calculation, $\mathrm{CF}_{\mathrm{t}}$ is cash flow at time $t$ and $r$ is an expected return of the stock. Estimating the cash flow duration requires forecasted cash flows up to the future time $t$, and the specific time $t$ is set by 40 (in quarter) as is in Weber (2018). Cash flow at future time $t$ is forecasted using an account identity, which is $B E_{t}=B E_{t-1}+E_{t}-C F_{t}$ or $B E_{t} / B E_{t-1}-1=E_{t} / B E_{t-1}-C F_{t} / B E_{t-1} \mathrm{BE}$ is a book value, $E$ is earnings and $\mathrm{E} / \mathrm{BE}$ is $\mathrm{ROE}$. The growth rate of $\mathrm{BE}$ is assumed to be the same with the growth rate of sales, and the growth of sales and ROE are assumed to follow $\mathrm{AR}(1)$ process, respectively. Under these assumptions, we can estimate the future 40 quarters' cash flows. Following Weber (2018), the coefficients of AR (1) processes of the ROE and growth of sales in the above duration model are defined as 0.41 and 0.24 , respectively. Long-term average growth rates of ROE and growth of sales are set by $12 \%$ and $6 \%$, and the interest rate $r$ is set by 0.12 . The duration is calculated at the end of June each year $t$, using the accounting data for the fiscal year end $t-1$ and the market value at the end of June of the year.

\subsection{Main factors}

3.3.1 Returns on momentum strategy. To reinforce robustness of empirical results, the return on the momentum strategy is extracted from the following three strategies. First, stocks listed in KOSPI are sorted based on their past returns at time $t$, and we keep the values of the bottom $10 \%$ and top $10 \%$ past returns to be used as breakpoints. Then, for all stocks listed in KOSPI or KOSDAQ, each stock is classified as loser if its past return is lower than the bottom $10 \%$ threshold and classified as winner if its past return is higher than the top $10 \%$ threshold. Next, the value-weighted return of the winner's portfolio at time $t+1$ is deducted from the value-weighted return of the loser's portfolio at time $t+1$, which is defined as the return of momentum strategy (WML10). Second, the KOSPI bottom 20\% $(30 \%)$ and the top $20 \%(30 \%)$ of past returns are used as breakpoint to produce WML20 (WML30) with the same preceding method.

3.3.2 Illiquidity factors by investor groups. We calculate the illiquidity factor by investor group (foreigner/institutional and individual) after controlling for firm size. First, the stocks listed on the KOSPI and KOSDAQ are classified as large and small stocks at the end of each month $t$ using the median market value of stocks listed on the KOSPI as breakpoints. Then, stocks for each size group are subdivided into high FIR and low FIR groups based on the median value of $\mathrm{FIR}_{i, t}$. We may assume that foreigners and institutions have led transactions on a stock for the past six months if the stock has the higher $\mathrm{FIR}_{i, t}$ ratio. Finally, for each of the four groups double-sorted by firm size and FIR, individual stocks are divided by the bottom $30 \%$, middle $40 \%$ and top $30 \%$ of the illiquidity characteristics, $I L L I Q_{i, t}$, calculating the value-weighted return for each portfolio. As a result, a total of 12 portfolios of $2 \times 2 \times 3$ is produced at monthly frequency. We calculate the arithmetic average of the portfolio returns consisting of stocks with top 30\% illiquidity in the large-high FIR group and the portfolio returns consisting of the top 30\% illiquidity in the small-high FIR group and the arithmetic average of the portfolio returns consisting of stocks with bottom $30 \%$ illiquidity in the large-high FIR group and the portfolio returns consisting of the bottom $30 \%$ illiquidity in small-high FIR group. Then, the difference in the two arithmetic averages is defined as a IML_FI, which is referred to as IML_FI (foreign/institutional illiquidity minus liquidity). The same approach is applied to the IML_ID (individual illiquidity minus liquidity), which is defined as the arithmetic average of returns of top $30 \%$ 
illiquidity portfolios in large-low FIR and small-low FIR minus the arithmetic average of returns of bottom $30 \%$ illiquidity portfolios in large-low FIR and small-low FIR.

For comparison, we also calculate the overall illiquidity factor that does not take into account investor group. Specifically, we divide entire stocks into large-cap and small-cap groups based on the median market value of the stocks listed in KOSPI. Then, we subdivide stocks for each size group into the bottom $30 \%$, median $40 \%$ and top $30 \%$ in order of the illiquidity characteristic of individual stocks and calculate the value-weighted returns of the portfolios. The arithmetic mean return of the top $30 \%$ illiquidity stocks in large-cap and

Korean stock market small-cap groups is deducted from the arithmetic mean return of the bottom $30 \%$ illiquidity stocks in large-cap and small-cap groups, which is defined as the overall illiquidity factor and denoted as IML (illiquidity minus liquidity).

3.3.3 Duration factor. We construct a duration factor using the duration of individual stocks, following the portfolio construction methodology of Fama and French (1993). Specifically, at the end of June in year $t$, we divide entire stocks into large-cap and small-cap groups using the breakpoints that are the median market value of the KOSPI-listed stocks and subdivide stocks for each size group into the bottom $30 \%$, median $40 \%$ and top $30 \%$ in order of the duration, resulting in a total of six portfolios. The portfolio formed at the end of June year $t$ are kept until the end of June year $t+1$, and the monthly returns of the portfolios are calculated by value-weighting returns of the individual stocks in each portfolio. The duration factor is then calculated by the average of the large-low duration portfolio and the small-low duration portfolio minus the average of the large-high duration portfolio and the small-high duration portfolio. We denote the duration factor as NMF (near minus far).

3.3.4 Other factors. We use several asset pricing models, CAPM, the FF3 and the FF5, to estimate risk-adjusted returns of stocks. The market return is defined as the value-weighted returns of the whole stocks listed in KOSPI. The other factors of FF3 or FF5 are constructed by following the methodology described by Famaand French (1993) and Fama and French (2015).

\section{Empirical results}

\subsection{Summary statistics}

Table 1 shows summary statistics for the main variables in this study. Panel A reports the mean, standard deviation, top $25 \%, 50 \%$ and $75 \%$ sample values for the variables, and Panel B represents the correlation matrix among the variables. Size is the logarithm of the market value, BM is the logarithm of the book value divided by the market value, Mom represents the sum of monthly returns for the past 12 months to 7 months, Illqis the logarithm of the illiquidity of individual stocks, FIR is the proportion of foreign and institutional trading volume to the total trading volume incurred in the past six months and Dur refers to the duration of individual stocks. The results of Table 1 can be summarized as follows. First, foreigners and institutions account for approximately $13 \%$ of the total transaction amount in the KOSPI and KOSDAQ during the sample period, which may be resulted from the low proportion of institutional and foreign transactions in the KOSDAQ market. It is supported by the high estimated correlation between FIR and firm size of 0.772 . In addition, the correlation between FIR and Illq is estimated to be -0.457 , which means that foreign and institutional investors trade stocks with relatively high liquidity. Second, the average duration of the firms included in our sample is estimated to be 12.50 years, while the bottom $25 \%$ and the top $25 \%$ values of duration are estimated to be 9.50 and 16.58 , respectively. In addition, the correlation between duration and BM is -0.527 , meaning that duration of value stocks is relatively lower than that of growth stocks, consistent with the US evidence from Lettau and Wachter (2007). 


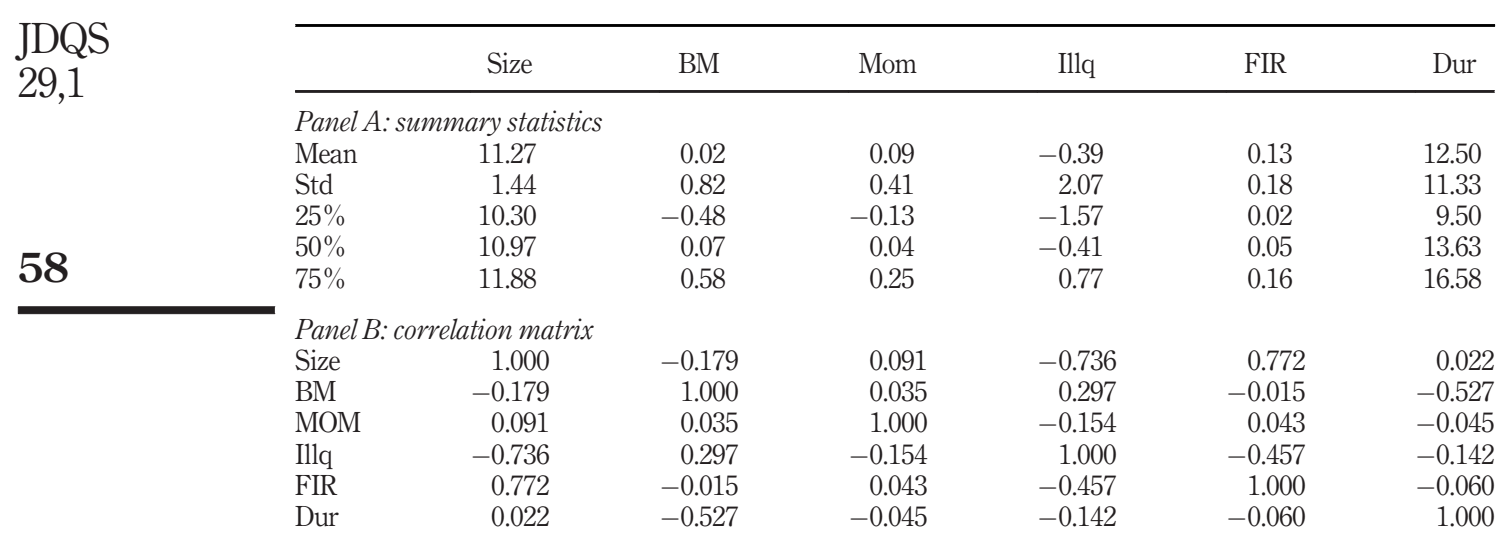

Notes: This table reports summary statistics for the main variables in this study. Panel A shows the mean, standard deviation, top $25 \%, 50 \%$ and $75 \%$ values of the variables, and Panel B shows the correlation matrix of the variables. Size is the logarithm of market value; BM is the logarithm of the book value divided by market value; Mom is a sum of the past 12 to 7 months returns; Illq is the logarithm of individual stocks'

Table 1.

Summary statistics illiquidity; FIR is the trading ratio of foreign and institutional investors for the past six months; Dur is individual stocks' duration. The sample period is from July 2001 to June 2019

Table 2 presents summary statistics of the main factors used in this study. We use the market factor (MKT), size factor (SMB), value factor (HML), profitability factor (RMW) and investment factor (CMA) to estimate risk-adjusted returns of individual stocks, and we use IML_FI, IML_ID and NMF to examine their relationship to momentum returns. Panel A reports monthly returns of the factors, and Panel $\mathrm{B}$ displays a correlation matrix among the factors. The results of Table 2 can be summarized as follows. First, the mean returns on the

\begin{tabular}{lccrrrrrr}
\hline & MKT & SMB & HML & RMW & CMA & IML_FI & IML_ID & NMF \\
\hline Panel A: summary statistics & & & & & & & \\
Mean & 0.63 & 0.15 & 1.35 & 0.52 & 0.22 & 0.77 & 1.39 & 1.32 \\
[t] & 1.47 & 0.35 & 4.88 & 2.50 & 1.06 & 3.92 & 4.92 & 4.95 \\
Std. & 5.75 & 5.00 & 4.29 & 3.37 & 3.49 & 3.17 & 4.61 & 3.80 \\
Panel B: correlation matrix & & & & & & & \\
MKT & 1.00 & 0.07 & 0.04 & 0.22 & 0.17 & -0.42 & -0.34 & 0.08 \\
SMB & 0.07 & 1.00 & -0.19 & -0.13 & -0.08 & -0.01 & -0.22 & -0.21 \\
HML & 0.04 & -0.19 & 1.00 & 0.41 & 0.14 & 0.44 & 0.27 & 0.71 \\
RMW & 0.22 & -0.13 & 0.41 & 1.00 & -0.17 & 0.13 & 0.24 & 0.42 \\
CMA & 0.17 & -0.08 & 0.14 & -0.17 & 1.00 & 0.00 & -0.31 & 0.16 \\
IML_FI & -0.42 & -0.01 & 0.44 & 0.13 & 0.00 & 1.00 & 0.49 & 0.45 \\
IML_ID & -0.34 & -0.22 & 0.27 & 0.24 & -0.31 & 0.49 & 1.00 & 0.33 \\
NMF & 0.08 & -0.21 & 0.71 & 0.42 & 0.16 & 0.45 & 0.33 & 1.00
\end{tabular}

Table 2.

Returns on main factors
Notes: This table presents summary statistics of monthly returns of the eight factors. Mean returns, their $t$ statistics and standard deviations of each factor are shown in Panel A, and the correlation matrix of the factors is shown in Panel B. The factors include the market (MKT), size (SMB), value (HML), profitability (RMW) and investment (CMA) factors in Fama-French's five-factor model, and the foreign/institutional illiquidity (IML_FI), individual illiquidity (IML_ID) and duration (NMF) factors introduced in this study. The sample period is from July 2001 to June 2019 
value and profitability factors among the five factors of Fama-French are statistically significant. In particular, the monthly average return on the value factor is estimated to be very large at $1.35 \%$ per month $(t$-values $=4.88)$, which is consistent with the results of prior studies in the Korean stock market (Kang et al., 2019). Second, the IML_FI and the IML_ID introduced in this study are significantly positive, implying that there is an illiquidity premium in the Korean stock market. In particular, the individual illiquidity premium turns out to be very high at $1.39 \%$, which could be related to the high proportion of transactions by individuals for stocks with relatively low liquidity. Third, the average monthly return of the duration factor is estimated to be also very high at $1.32 \%$ per month $(t$-values $=4.95)$, which means that the returns of short duration stocks are higher than the returns of long duration stock. Fourth, the correlation between the HML and NMF factors is found to be 0.71 , and this high correlation is also consistent with the results of Table 1 in which value stocks have shorter duration than growth stocks. Although the correlation between the two factors is high, there is a possibility that the two factors have different explanatory power over the momentum strategy returns. We consider this issue later.

Table 3 shows the mean excess returns and risk-adjusted returns on the portfolios of winners, losers and the winner minus loser stocks. Panel A represents the results of equally weighted portfolios, and Panel B displays the results of value-weighted portfolios. To
Korean stock market

\begin{tabular}{lrrrrrrrrr}
\hline Risk-adjusted returns & L10 & W10 & WML10 & L20 & W20 & WML20 & L30 & W30 & WML30 \\
\hline Panel A: equal-weighted & & & & & & & & & \\
Excess $r$ & -0.14 & 0.70 & 0.84 & 0.27 & 0.93 & 0.65 & 0.50 & 1.00 & 0.50 \\
{$[t]$} & -0.23 & 1.24 & 3.36 & 0.47 & 1.67 & 3.15 & 0.88 & 1.82 & 2.84 \\
CAPM $\alpha$ & -0.75 & 0.06 & 0.81 & -0.33 & 0.29 & 0.62 & -0.10 & 0.37 & 0.47 \\
{$[t]$} & -1.84 & 0.16 & 3.44 & -0.88 & 0.85 & 3.12 & -0.27 & 1.15 & 2.83 \\
FF3 $\alpha$ & -0.77 & -0.09 & 0.68 & -0.40 & 0.09 & 0.49 & -0.22 & 0.14 & 0.36 \\
{$[t]$} & -2.88 & -0.42 & 2.56 & -1.88 & 0.50 & 2.27 & -1.13 & 0.90 & 1.94 \\
FF5 $\alpha$ & -0.73 & -0.05 & 0.68 & -0.37 & 0.13 & 0.49 & -0.18 & 0.18 & 0.36 \\
{$[t]$} & -3.25 & -0.23 & 2.62 & -2.12 & 0.76 & 2.32 & -1.19 & 1.23 & 2.00 \\
Panel B: value-weighted & & & & & & & & & \\
Excess $r$ & -0.18 & 0.58 & 0.76 & 0.03 & 1.08 & 1.06 & 0.27 & 1.10 & 0.83 \\
{$[t]$} & -0.33 & 1.03 & 1.58 & 0.06 & 2.06 & 2.53 & 0.61 & 2.15 & 2.43 \\
CAPM $\alpha$ & -0.88 & -0.11 & 0.77 & -0.61 & 0.40 & 1.01 & -0.33 & 0.42 & 0.75 \\
{$[t]$} & -2.78 & -0.36 & 1.61 & -2.37 & 1.68 & 2.47 & -1.75 & 2.26 & 2.31 \\
FF3 $\alpha$ & -0.78 & -0.29 & 0.50 & -0.55 & 0.35 & 0.89 & -0.32 & 0.38 & 0.69 \\
{$[t]$} & -2.61 & -1.04 & 1.08 & -2.29 & 1.41 & 2.17 & -1.89 & 2.01 & 2.19 \\
FF5 $\alpha$ & -0.77 & -0.28 & 0.49 & -0.53 & 0.34 & 0.87 & -0.31 & 0.38 & 0.68 \\
{$[t]$} & -2.60 & -1.02 & 1.10 & -2.22 & 1.39 & 2.14 & -1.83 & 2.02 & 2.15
\end{tabular}

Notes: This table represents the excess and risk-adjusted returns of the three momentum strategies. Equalweighted and value-weighted portfolio results are shown in Panel A and B, respectively. The risk-adjusted returns $(\alpha)$ are calculated by the CAPM, the Fama-French three-factor model (FF3) and the Fama-French five-factor model (FF5). To construct portfolios based on past returns, we sort stocks listed in KOSPI based on past returns as the sum of the monthly returns from the end of the month $t-11$ to the end of the month $t-6$ as of the end of each month $t$, and keep the values of the bottom $10 \%$ and top $10 \%$ values to be used as breakpoints. Then, for all of the stocks listed in KOSPI or KOSDAQ, each stock is classified as loser if its past return is lower than the bottom $10 \%$ threshold and classified as winner if its momentum characteristic is higher than the top $10 \%$ threshold. Next, the value-weighted return of the winner's portfolio at time $t+1$ is deducted from the value-weighted return of the loser's portfolio at time $t+1$, which is defined as the return of momentum strategy (WML10). With the same preceding method, we calculate the returns of momentum strategies (WML20) and (WML30). All $t$-statistics are consistent with the Newey-West's (1987) correction with lag 4. The sample period is from July 2001 to June 2019
Table 3.

Excess and riskadjusted returns of the momentum strategy 
JDQS 29,1

estimate the risk-adjusted returns, we use the CAPM, FF3 and FF5. In Panel A, the average monthly returns for the three strategies, WML10, WML20 and WML30, are all statistically significant with their values of $0.84 \%, 0.65 \%$ and $0.50 \%$ per month, respectively. The riskadjusted returns are statistically significant as well, implying that the existing asset pricing models cannot explain the momentum effect in the Korean stock market. In Panel B, we find the similar results to those of Panel A. However, the mean return on the WML10 portfolio is not statistically significant at the $5 \%$ level.

Consequently, the results in Table 3 indicate that there is the momentum effect in the Korean stock market, and it is not explained by the existing asset pricing models such as the CAPM, the FF3 and the FF5.

\subsection{Illiquidity factor and momentum strategy returns}

In this subsection, we examine the explanatory power of the illiquidity factor for momentum profit. We examine the relation between the illiquidity factor and the momentum profit because prior works report that momentum profit is significantly related to market liquidity (Avramov et al., 2016; Kim and Lee, 2018). In general, when market liquidity increases, the return on stocks with relatively low liquidity is higher than the return on stocks with relatively high liquidity, and thus, the illiquidity factor is likely to earn a positive return. Therefore, if the momentum strategy has better performance when market liquidity improves as found in prior research, then the illiquidity factor can explain the performance of the momentum strategy. Moreover, we divide the illiquidity factor as the foreign/ institutional and IML_ID to reflect the empirical evidence from prior studies. For example, Kim and Lee (2018) document that the momentum effect has emerged since the IMF crisis when foreign investors began to actively trade, and Kang et al. (2014) find that momentum investment strategies of foreign investors after the IMF crisis are related to the existence of the momentum effect in the Korean stock markets.

Table 4 presents the average and risk-adjusted returns for the overall illiquidity factor (IML), IML_FI and IML_ID. Specifically, Panel A presents the average returns for each illiquidity factor and their Newey-West $t$-statistics, and Panels B-D present the riskadjusted returns of each illiquidity factor and their Newey-West $t$-statistics with CAPM, the FF3 and the FF5, respectively. The results of Table 4 can be summarized as follows. First, all illiquidity factors have significantly positive mean returns. This is consistent with the results of prior research (Jang et al., 2012), which argue that the illiquidity premium exists in the Korean stock market. The mean return of IML_ID is estimated at $1.39 \%$ per month, and the mean return of IML_FI is estimated at $0.77 \%$ per month, which means that the illiquidity premium is higher in stocks with a relatively high proportion of individual transactions. Second, the alphas for the three illiquidity factors turn out to be statistically significant regardless of the models used for risk-adjusting, which indicates that the existing asset pricing models do not properly explain the illiquidity premium. This implies the possibility that the illiquidity factors have different information which is distinct from factors in the existing asset pricing models.

Table 5 shows the results of time-series regressions where the value-weighted returns of the three momentum strategies are used as a dependent variable, and the factors in the existing asset pricing model, IML, IML_FI and IML_ID are used as independent variables. The asset pricing models used in the regressions are the CAPM, the FF3 and the FF5. Panel A reports the average returns on the individual momentum strategies, and Panel B reports the results of time-series regressions using the overall illiquidity factor along with the factors of each asset pricing model as explanatory variables, as in a form of equation (4): 


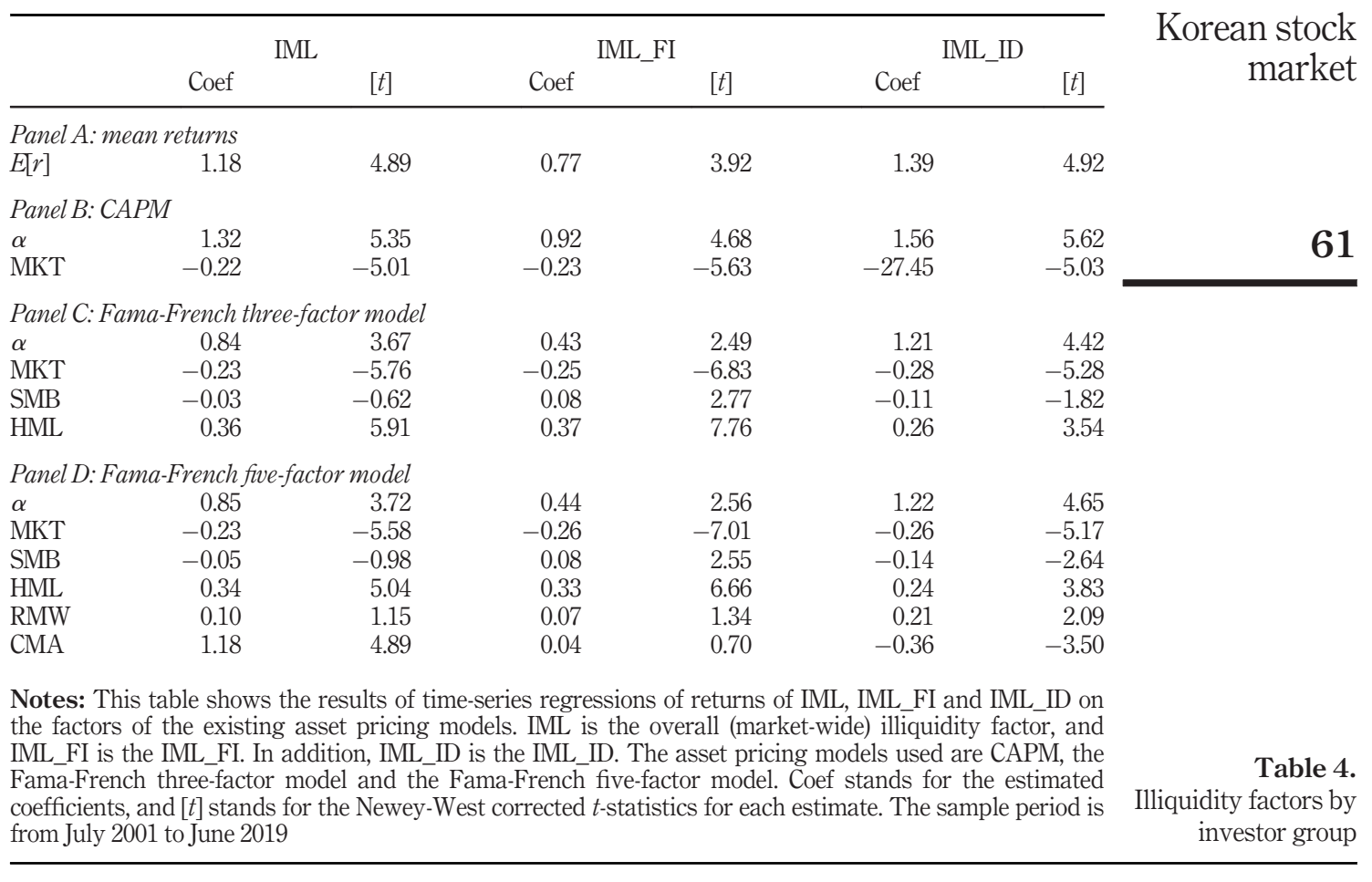

$$
r_{\mathrm{t}}=\alpha+\beta^{I M L} I M L_{t}+\sum_{i} \gamma_{i} \text { Factors }_{t}^{i}+\epsilon_{\mathrm{t}}
$$

$r_{\mathrm{t}}$ is a return of the momentum strategies at time $t$, and Factors ${ }_{t}^{i}$ is a time $t$ return of factor $i$ included in the asset pricing models consisting of CAPM, FF3 and FF5. To save space, we only report the alpha and beta on the illiquidity factor for the momentum strategies. The $t$ statistics for each estimate are corrected by Newey-West estimation with lags of 4 .

Looking at the results of WML20 and WML30 as dependent variables, the coefficient on IML is $0.10-0.16$, and most of their $t$-statistics are lower than 1 . This means that the overall illiquidity factor cannot explain the momentum effect. Based on the prior research, we ask whether the IML_FI has an explanatory power for the momentum effect. To this end, the time-series regressions are conducted as shown in equation (5) in which the monthly return of each momentum strategy is a dependent variable, and the foreign/institutional and IML_ID in addition to the factors of individual asset pricing models are used as independent variables. The results are reported in Panel C of Table 5:

$$
r_{\mathrm{t}}=\alpha+\beta^{I M L_{-} F I} I M L_{-} F I_{t}+\beta^{I M L_{-} I D} I M L_{-} I D_{t}+\sum_{i} \gamma_{i} \text { Factors }_{t}^{i}+\epsilon_{\mathrm{t}}
$$

The results that use WML20 and WML30 as dependent variables can be summarized as follows. First, the estimated coefficients of IML_ID are -0.03 to 0.11 , and the absolute values of the $t$-statistics are all lower than 1 . In other words, the explanatory power of the IML_ID for the momentum effect does not exist in the Korean stock market. Second, the estimated 


\section{JDQS 29,1}

\begin{tabular}{|c|c|c|c|c|c|c|c|}
\hline \multirow[t]{2}{*}{ Model } & & \multicolumn{2}{|c|}{ WML10 } & \multicolumn{2}{|c|}{ WML20 } & \multicolumn{2}{|c|}{ WML30 } \\
\hline & & Coef & {$[t]$} & Coef & {$[t]$} & Coef & {$[t]$} \\
\hline & \multicolumn{7}{|c|}{ Panel A: average momentum profits } \\
\hline & $E[r]$ & 0.76 & 1.58 & 1.06 & 2.53 & 0.83 & 2.43 \\
\hline \multirow{3}{*}{$+\mathrm{CAPM}$} & \multicolumn{7}{|c|}{ Panel B: regression results with IML as an independent variable } \\
\hline & $\alpha$ & 0.34 & 0.71 & 0.81 & 1.86 & 0.56 & 1.58 \\
\hline & $\beta^{I M L}$ & 0.32 & 2.19 & 0.16 & 1.05 & 0.13 & 1.07 \\
\hline \multirow[t]{2}{*}{$+\mathrm{FF} 3$} & $\alpha$ & 0.25 & 0.51 & 0.80 & 1.87 & 0.57 & 1.67 \\
\hline & $\beta^{I M L}$ & 0.29 & 1.74 & 0.11 & 0.68 & 0.11 & 0.83 \\
\hline \multirow[t]{3}{*}{$+\mathrm{FF} 5$} & $\alpha$ & 0.27 & 0.58 & 0.79 & 1.85 & 0.56 & 1.64 \\
\hline & $\beta^{I M L}$ & 0.25 & 1.46 & 0.10 & 0.58 & 0.11 & 0.77 \\
\hline & \multicolumn{7}{|c|}{ Panel C: regression results with $I M L \_F I$ and IML_ID as independent variables } \\
\hline \multirow[t]{3}{*}{$+\mathrm{CAPM}$} & $\alpha$ & 0.29 & 0.60 & 0.82 & 1.87 & 0.56 & 1.58 \\
\hline & $\beta^{I M L \_F I}$ & 0.35 & 2.08 & 0.29 & 1.71 & 0.21 & 1.59 \\
\hline & $\beta^{I M L \_I D}$ & 0.10 & 0.69 & -0.05 & -0.35 & -0.02 & -0.15 \\
\hline \multirow[t]{3}{*}{$+\mathrm{FF} 3$} & $\alpha$ & 0.23 & 0.47 & 0.86 & 2.00 & 0.60 & 1.77 \\
\hline & $\beta^{I M L \_F I}$ & 0.30 & 1.45 & 0.31 & 1.67 & 0.25 & 1.62 \\
\hline & $\beta^{I M L \_I D}$ & 0.12 & 0.78 & -0.08 & -0.60 & -0.04 & -0.32 \\
\hline \multirow[t]{3}{*}{$+\mathrm{FF} 5$} & $\alpha$ & 0.32 & 0.69 & 0.87 & 2.04 & 0.62 & 1.79 \\
\hline & $\beta^{I M L \_F I}$ & 0.32 & 1.57 & 0.29 & 1.56 & 0.25 & 1.65 \\
\hline & $\beta^{I M L \_I D}$ & 0.02 & 0.13 & -0.11 & -0.69 & -0.06 & -0.47 \\
\hline
\end{tabular}

Notes: This table reports the time-series regression results in which the value-weighted returns of the three momentum strategies are regressed by the illiquidity factors and factors of CAPM, the Fama-French threefactor model (FF3) or the Fama-French five-factor model (FF5). IML, IML_FI and IML_ID are the overall (market-wide) illiquidity factor, IML_FI and IML_ID, respectively. The mean returns are presented in Panel $\mathrm{A}$, and the regression results of momentum returns on IML and factors of the existing asset pricing models are shown in Panel B:

$$
r_{t}=\alpha+\beta^{I M L} I M L_{t}+\sum_{i} \gamma_{i} \text { Factors }_{t}^{i}+\epsilon_{t}
$$

$r_{t}$ is the momentum return at time $t$, and Factors ${ }_{t}^{i}$ are the returns on factors of CAPM, the Fama-French three-factor model or the Fama-French five-factor model. In Panel C, the regression results of momentum returns on IML_FI, IML_ID and factors of the existing asset pricing models are represented

Table 5.

Regression results of momentum profits on illiquidity factors

$$
r_{t}=\alpha+\beta^{I M L \_F I} I M L \_F I_{t}+\beta^{I M L \_I D} I M L \_I D_{t}+\sum_{i} \gamma_{i} \text { Factors }_{t}^{i}+\epsilon_{t}
$$

To save the space, we only report alphas and betas on each illiquidity factor. $[t]$ stands for the Newey-West $t$-statistics with lag 4. The sample period is from July 2001 to June 2019

coefficients of IML_FI are $0.21-0.29$, and when compared with the estimated coefficients of IML_ID that are almost zero, it can be inferred that the IML_FI is a much more important factor in understanding the momentum effect. Furthermore, considering that all of the estimated coefficients for IML_FI are positive and that the average return for IML_FI is $0.77 \%$, the IML_FI helps to explain the mean returns of the momentum strategy. In addition, the $t$-statistics of IML_FI are 1.56-1.71, with some coefficients estimated statistically significant at the $10 \%$ level. Consequently, the results in Table 5 indicate that the IML_FI has explanatory power on the momentum effect in the Korean stock market. 


\subsection{Duration factor and momentum strategy returns}

4.3.1 Duration factor. In this subsection, we examine the explanatory power of the duration factor for the momentum strategy returns. Traditionally, duration has been very important in analyzing the bond market, but recent studies have also focused on duration to explain the cross-sectional differences in stock returns (Lettau and Wachter, 2007; Chen and Yang, 2019; Moon and Song, 2019).Guided by the related literature, we also examine the explanatory power of the duration factor for the momentum profits.

To analyze duration and the performance of the momentum strategy, we first investigate market the relation between the duration and the stock returns. In particular, as with prior studies, we examine whether there is a negative relation between the duration and stock returns. To do so, we divide firms into decile groups sorted by the duration and examine the holdingperiod returns of the decile portfolios, which is presented in Table 6. Panel A represents the results of the equal-weighted portfolio, and Panel B displays value-weighted portfolio results. Specifically, they include the average monthly excess return (Raw $\alpha$ ) for the decile portfolios and the alphas of the CAPM, the FF3 and the FF5.

The results of Table 6 are summarized as follows. First, as in the prior studies, stocks with shorter (longer) duration earn higher (lower) average returns. For the equal- (value-) weighted case, the lowest decile duration portfolio has a higher monthly average return by $2.85 \%(1.56 \%)$ per month than the highest decile duration portfolio, and the return difference is statistically significant. In addition, it can be inferred that the difference in returns between the lowest and highest duration portfolio is highly economically significant considering that the average monthly returns for WML10, WML20 and WML30 are $0.76 \%$, $1.06 \%$ and $0.83 \%$, respectively. Second, the difference in returns between the lowest and highest duration portfolio is not explained by the competing asset pricing models. In the case of CAPM, the alphas of the equal-weighted and value-weighted returns have a

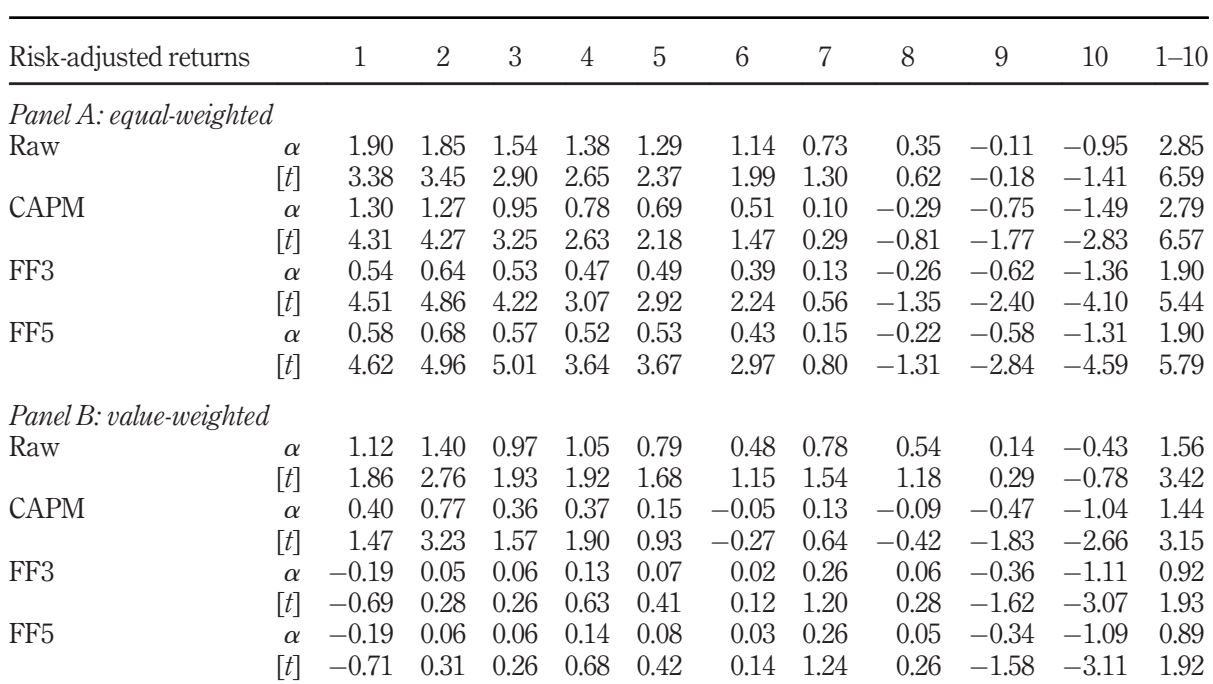

Notes: This table shows the equally-weighted (Panel A) and value-weighted (Panel B) returns of decile portfolios sorted by the duration and their alphas $(\alpha)$ for CAPM, the Fama-French three-factor model (FF3) and the Fama-French five-factor model (FF5). [ $t$ ] stands for the Newey-West $t$-statistics with lag 4 . The sample period is from July 2001 to June 2019

Table 6.

Decile portfolios sorted by duration 
JDQS 29,1

statistically significantly positive value, and the magnitude of the alphas is almost equal to the average return of each portfolio, implying that CAPM does not capture the relation between the duration and the stock returns. For the two Fama-French models, the magnitude of alphas is somewhat attenuated, but it is still statistically significant.

Consequently, the difference in returns between short-term and long-term duration stocks is economically and statistically significant and not explained by the existing asset pricing models. This indicates that the duration factor is further exposed to risks distinguished from the existing factors for future stock returns, providing a risk premium. As one source of the additional risks, the time preference risk (longevity risk) suggested by Chen and Yang (2019) may be considered. Longer duration stocks earn relatively low returns because those stocks can be used for a hedge against the bad risk of a sudden decrease in wealth induced by an increase in investors' life expectancy. As a result, the empirical results of our study that stocks with lower duration show better performance are consistent with the existing literature documenting that the longevity risk is negatively priced.

To ensure that the duration factor contains additional risks that the existing factors do not capture for future stock returns and that the risks are properly priced, we conduct a spanning test with existing factors. The spanning test includes the five factors of FamaFrench, the IML_FI and IML_ID formed in Section 4.2 and the duration factor. The results are tabulated in Table 7. First, looking at the results of the spanning tests for each factor of the Fama-French five-factor model, only the market factor (MKT) generates statistically significant constant with $t$-values of 2.17 , indicating that only the market factor among the Fama-French's five factors is not explained by the remaining factors. Furthermore, the value factor (HML) is known to earn a significant premium in the Korean stock market, but we find that the constant of HML in the spanning test is not statistically significant, mainly resulted from the high explanatory power of IML_FI and NMF. Second, examining the results of the spanning tests for each IML_FI and IML_ID, we find that the illiquidity factors for each investor group are not explained by the Fama-French five-factor model, consistent with the results in Section 4.2. However, when adding the duration factor to the FamaFrench five-factor model, the coefficient on the duration factor is statistically significant, and the constant term for the IML_FI loses its statistical significance. Third, when the duration factor is served as a dependent variable, the constant term becomes statistically insignificant when adding the IML_FI and IML_ID to the Fama-French five-factor model, although the duration factor is not spanned by the Fama-French five-factor model itself. In particular, the slope on IML_FI and IML_ID is estimated at 0.27 and 0.11 , respectively, which indicates that the duration factor is more closely related to the foreign/institutional illiquidity factor.

To sum up, the results in Table 7 show that the duration factor return is related to the return on the illiquidity factors of the two investor groups, especially the duration factor is more linked to the IML_FI. In general, when market liquidity is high, the return on relatively illiquid stocks is higher than the return on liquid stocks, and thus it is likely that the return of the illiquidity factor is realized at a higher value. In addition, when the market liquidity rises, investors may prefer assets with a relatively short maturity owing to the expectation of increasing future interest rates, which increases demand for assets with lower duration, resulting in a positive realized return of the duration factor. The result that the duration factor is highly related to the IML_FI means that foreigners and institutions are more sensitive to the duration of stocks. In other words, the utility of foreign and institutional investors is more sensitive to a fluctuation in time preferences than the utility of individual investors, which may be related with the fact that pension funds and insurers, the leading institutional investors, are heavily affected by life expectancy. 


\begin{tabular}{|c|c|c|c|c|c|c|c|c|c|}
\hline \multirow{2}{*}{$\begin{array}{l}\text { Dep. } \\
\text { var. }\end{array}$} & \multicolumn{9}{|c|}{ Independent var. } \\
\hline & Const & MKT & SMB & HML & RMW & CMA & IML_FI & IML_ID & $\mathrm{NMF}$ \\
\hline MKT & 0.81 & & 0.15 & 0.04 & 0.43 & 0.20 & -0.88 & -0.23 & \\
\hline$[t]$ & 2.17 & & 1.69 & 0.34 & 3.17 & 1.74 & -7.04 & -2.84 & $z$ \\
\hline SMB & 0.61 & 0.15 & & -0.12 & -0.09 & -0.24 & 0.52 & -0.30 & -0 \\
\hline$[t]$ & 1.50 & 1.80 & & -1.07 & -0.81 & -2.02 & 4.19 & -3.34 & -1 \\
\hline HML & 0.24 & 0.02 & -0.04 & & 0.21 & 0.07 & 0.26 & -0.03 & 0 \\
\hline$[t]$ & 1.10 & 0.34 & -1.05 & & 2.72 & 1.01 & 2.82 & -0.59 & \\
\hline RMW & -0.15 & 0.16 & -0.03 & 0.20 & & -0.25 & -0.02 & 0.09 & 0.2 \\
\hline$[t]$ & -0.85 & 3.75 & -0.79 & 3.02 & & -4.28 & -0.27 & 1.45 & 2.6 \\
\hline CMA & 0.24 & 0.09 & -0.10 & 0.08 & -0.29 & & 0.16 & -0.30 & 0.2 \\
\hline$[t]$ & 1.12 & 1.82 & -1.89 & 0.99 & -4.46 & & 1.80 & -3.22 & \\
\hline IML_FI & 0.44 & -0.26 & 0.08 & 0.33 & 0.07 & 0.04 & & & \\
\hline$[t]$ & 2.56 & -7.01 & 2.55 & 6.66 & 1.34 & 0.70 & & & \\
\hline IML_FI & 0.30 & -0.26 & 0.09 & 0.16 & 0.01 & 0.00 & & & 0. \\
\hline$[t]$ & 1.74 & -7.24 & 3.06 & 2.83 & 0.27 & 0.11 & & & \\
\hline IML_ID & 1.22 & -0.26 & -0.14 & 0.24 & 0.21 & -0.36 & & & \\
\hline & 4.65 & -5.17 & -2.64 & 3.83 & 2.09 & -3.50 & & & \\
\hline IML_ID & 1.05 & -0.26 & -0.12 & 0.04 & 0.14 & -0.40 & & & 0 \\
\hline$[t]$ & 4.00 & -5.22 & -2.24 & 0.57 & 1.37 & -4.12 & & & \\
\hline NMF & 0.47 & 0.01 & -0.05 & 0.54 & 0.19 & 0.11 & & & \\
\hline$[t]$ & 2.27 & 0.13 & -1.01 & 8.14 & 3.21 & 1.66 & & & \\
\hline $\mathrm{NMF}$ & 0.22 & 0.10 & -0.06 & 0.43 & 0.15 & 0.14 & 0.27 & 0.11 & \\
\hline$[t]$ & 1.04 & 2.07 & -1.20 & 6.78 & 2.53 & 2.39 & 3.16 & 2.33 & \\
\hline
\end{tabular}

Korean stock market

Notes: This table reports the results of spanning tests. The spanning test of a specific factor $i$ with respect to a specific factor model $\mathrm{M}$ is conducted as follows:

$$
f_{t}^{i}=\alpha^{i}+\sum_{j \in M} \gamma_{i} f_{t}^{j}+\epsilon_{\mathrm{t}}
$$

where $f_{t}^{i}$ is a return of the specific factor at time $t$, and $f_{t}^{j}$ is a return at time $t$ of factor $j$ included in the specific factor model M. Factors used in the spanning tests are the market (MKT), size (SMB), value (HML), profitability (RMW), investment (CMA), foreign/institutional illiquidity (IML_FI), individual illiquidity (IML_ID) and duration (NMF) factors. [t] stands for the Newey-West-corrected $t$-statistics with lag 4 . The sample period is from July 2001 to June 2019

Table 7. Spanning tests

Now we examine whether the duration is reasonably linked with the term-structure of stock returns. If the duration measure presented in this study works properly, firms with short (long) duration should be the firms proceeding projects focusing mainly on relatively shortterm (long-term) profits. To test this argument, we investigate exposures to the duration factor of the 25 industry returns provided by FnGuide. By the definition of the duration factor, the higher exposure implies that the industry focuses more on short-term profitability. Exposure to the duration factor of a specific industry is estimated by a timeseries regression of excess returns of the industry on the market and duration factor. The estimated exposures are presented in Table 8.

Notable findings in Table 8 are as follows. First, the medical equipment/services, semiconductors and software industries show the low exposure to the duration factor, and it is known that these industries focus relatively more on long-term future profitability. In particular, the estimated exposure of the medical equipment/services industry is very low 


\begin{tabular}{|c|c|c|c|c|c|c|c|}
\hline $\begin{array}{l}\text { JDQS } \\
29,1\end{array}$ & Industry & $\alpha$ & $\begin{array}{c}\beta_{\mathrm{NMF}} \\
\text { Coefficients }\end{array}$ & $\beta_{\text {MKT }}$ & $\alpha$ & $\beta_{\mathrm{NMF}}$ & $\beta_{\mathrm{MKT}}$ \\
\hline \multirow{25}{*}{66} & Eneroy & -0.30 & 0.36 & 103 & -0.63 & 257 & 968 \\
\hline & Materials & -0.51 & 0.37 & 1.00 & -2.14 & 4.97 & $\begin{array}{r}.0 .32 \\
192\end{array}$ \\
\hline & Capital goods & -0.56 & 0.23 & 1.22 & -1.82 & 1.95 & 15.51 \\
\hline & Commercial service & 0.05 & -0.09 & 0.67 & 0.14 & -0.92 & 7.65 \\
\hline & Transportation & -0.90 & 0.59 & 1.24 & -2.43 & 3.70 & 14.84 \\
\hline & Motor vehicles and parts & 0.19 & -0.05 & 1.07 & 0.52 & -0.46 & 17.13 \\
\hline & Consumer durables and clothes & 0.25 & -0.06 & 0.96 & 0.78 & -0.59 & 12.31 \\
\hline & Consumer service & 0.74 & -0.48 & 0.95 & 0.73 & -1.03 & 5.19 \\
\hline & Media & -0.15 & -0.31 & 0.80 & -0.40 & -3.79 & 9.31 \\
\hline & Distribution & -0.29 & 0.18 & 0.93 & -0.86 & 1.73 & 12.46 \\
\hline & Food/beverage and tobacco & 0.28 & -0.03 & 0.47 & 1.08 & -0.42 & 11.93 \\
\hline & Daily necessities & 0.77 & 0.06 & 0.70 & 1.56 & 0.46 & 7.32 \\
\hline & Medical device/service & 0.42 & -0.57 & 1.02 & 0.75 & -4.54 & 9.32 \\
\hline & Drug and bio & 1.01 & -0.28 & 0.80 & 2.07 & -2.13 & 9.47 \\
\hline & Bank & -0.29 & 0.06 & 1.07 & -1.00 & 0.60 & 14.34 \\
\hline & Other financial institutions & -0.65 & -0.27 & 1.06 & -0.84 & -1.16 & 9.66 \\
\hline & Insurance & 0.11 & 0.11 & 0.94 & 0.38 & 1.22 & 11.51 \\
\hline & Real estates & -0.54 & 0.03 & 0.67 & -0.97 & 0.22 & 5.26 \\
\hline & Securities & -0.56 & 0.08 & 1.54 & -1.27 & 0.72 & 18.26 \\
\hline & Software & 0.32 & -0.47 & 0.98 & 0.71 & -4.55 & 10.79 \\
\hline & Hardware & -0.34 & -0.23 & 1.08 & -0.94 & -2.67 & 14.12 \\
\hline & Semiconductors & 1.29 & -0.52 & 1.00 & 3.16 & -4.48 & 8.64 \\
\hline & Display & -0.60 & -0.38 & 1.13 & -1.36 & -2.89 & 11.68 \\
\hline & Telecommunication & -0.19 & -0.19 & 0.45 & -0.51 & -1.90 & 7.33 \\
\hline & Utilities & -0.46 & 0.15 & 0.49 & -1.24 & 1.52 & 7.78 \\
\hline
\end{tabular}

Table 8.

Regression results of industry portfolios on duration factor
Notes: This table shows the results of time-series regressions of 25 industry portfolios' monthly returns on the duration factor and market factor. $\beta_{\mathrm{NMF}}$ and $\beta_{\mathrm{MKT}}$ are the estimated betas on the duration factor and market factor, respectively. The industry classification is based on the classification code provided by Fnguide. [t] stands for the Newey-West $t$-statistics with lag 4 . The sample period is from July 2001 to June 2019

at -0.57 . Second, the transportation, energy, materials and distribution industries show the high exposure, especially the transportation industry with the highest exposure of 0.59 . The transportation, energy and distribution industries are typically considered as an industry pursuing short-term future profitability, and the materials industry has relatively high exposure to the duration factor owing to the nature of the intermediate goods industry. In sum, the results in Table 8 indicate that the duration measure and the duration factor presented in this study capture the term-structure representing sensitivity of firms to shortor long-term future profitability.

4.3.2 Duration and momentum strategy returns. Now, we examine the explanatory power of the duration factor for the momentum strategy returns. The economic reason for the link between the momentum returns and duration factor is based on the fact that winners have relatively shorter duration than losers, exposing them to the time preference risk (or longevity risk) negatively [3]. Thus, winners should have a relatively higher exposure to the duration factor than losers. To verify that the momentum returns are directly related to the duration factor, we run a time-series regression of monthly returns of the three momentum strategies on the market and duration factor, and the regression results are presented in Table 9 . 


\begin{tabular}{|c|c|c|c|c|c|c|c|c|}
\hline & \multicolumn{4}{|c|}{ Coefficients } & \multicolumn{4}{|c|}{$[t]$} \\
\hline $\begin{array}{l}\alpha \\
\beta_{\mathrm{MKT}} \\
\beta_{\mathrm{NMF}} \\
\text { Explaining Dur2 }^{\text {Dura }} \\
\text { Explaining } \\
\text { Explaining }\end{array}$ & $\begin{array}{r}\mathrm{L} 10 \\
-0.45 \\
1.11 \\
-0.33\end{array}$ & $\begin{array}{r}\text { M80 } \\
0.15 \\
0.98 \\
-0.04\end{array}$ & $\begin{array}{r}\text { W10 } \\
-0.20 \\
1.08 \\
0.07\end{array}$ & $\begin{array}{c}\text { WML10 } \\
0.25 \\
-0.03 \\
0.40 \\
0.67 \\
0.35 \\
0.36\end{array}$ & $\begin{array}{c}\text { L10 } \\
-1.40 \\
15.14 \\
-4.50\end{array}$ & $\begin{array}{r}\text { M80 } \\
2.83 \\
92.57 \\
-2.60\end{array}$ & $\begin{array}{r}\mathrm{W} 10 \\
-0.64 \\
16.54 \\
0.59\end{array}$ & $\begin{array}{c}\text { WML10 } \\
0.52 \\
-0.27 \\
2.79\end{array}$ \\
\hline $\begin{array}{l}\alpha \\
\beta_{\mathrm{MKT}} \\
\beta_{\mathrm{NMF}} \\
\text { Explaining }^{\text {Dur2 }} \\
\text { Explaining }^{\mathrm{FF} 3} \\
\text { Explaining }^{\mathrm{FF} 5}\end{array}$ & $\begin{array}{r}\text { L20 } \\
-0.21 \\
1.02 \\
-0.31\end{array}$ & $\begin{array}{r}\text { M60 } \\
0.05 \\
0.98 \\
-0.05\end{array}$ & $\begin{array}{c}\text { W20 } \\
0.23 \\
1.06 \\
0.13\end{array}$ & $\begin{array}{c}\text { WML20 } \\
0.45 \\
0.04 \\
0.44 \\
0.58 \\
0.15 \\
0.18\end{array}$ & $\begin{array}{c}\text { L20 } \\
-0.83 \\
17.30 \\
-4.22\end{array}$ & $\begin{array}{r}\text { M60 } \\
0.62 \\
50.27 \\
-1.89\end{array}$ & $\begin{array}{r}\text { W20 } \\
0.91 \\
18.20 \\
1.66\end{array}$ & $\begin{array}{c}\text { WML20 } \\
1.06 \\
0.40 \\
3.52\end{array}$ \\
\hline $\begin{array}{l}\alpha \\
\beta_{\mathrm{MKT}} \\
\beta_{\mathrm{NMF}} \\
\text { Explaining }^{\text {Dur2 }} \\
\text { Explaining }^{\mathrm{FF} 3} \\
\text { Explaining }^{\mathrm{FF} 5}\end{array}$ & $\begin{array}{r}\text { L30 } \\
-0.07 \\
0.96 \\
-0.21\end{array}$ & $\begin{array}{r}\mathrm{M} 40 \\
0.00 \\
0.98 \\
-0.02\end{array}$ & $\begin{array}{c}\text { W30 } \\
0.32 \\
1.07 \\
0.08\end{array}$ & $\begin{array}{c}\text { WML30 } \\
0.39 \\
0.12 \\
0.28 \\
0.54 \\
0.17 \\
0.19\end{array}$ & $\begin{array}{c}\text { L30 } \\
-0.34 \\
18.83 \\
-3.44\end{array}$ & $\begin{array}{c}\text { M40 } \\
-0.01 \\
35.99 \\
-0.65\end{array}$ & $\begin{array}{r}\text { W30 } \\
1.56 \\
21.67 \\
1.18\end{array}$ & $\begin{array}{c}\text { WML30 } \\
1.10 \\
1.30 \\
2.68\end{array}$ \\
\hline
\end{tabular}

Korean stock market

Notes: This table reports regression results of the three momentum strategies' returns on the duration factor and the market factor. $\beta_{\mathrm{NMF}}$ and $\beta_{\mathrm{MKT}}$ are the estimated betas on the duration and market factor, respectively. "Explaining (proportion)" means the explanatory power of a specific factor model for momentum returns and is calculated as follows:

$$
\text { Explaining }^{M}=\frac{\sum_{i \in M} \beta_{i} E\left[f_{i}\right]}{\mathrm{E}[\mathrm{r}]},
$$

where $\mathrm{M}$ indicates the specific factor model, $i$ indexes factors included in $\mathrm{M}, E\left[f_{i}\right]$ is the mean return of factor $i, \beta_{i}$ is beta of the momentum returns to factor $i$ and $E[r]$ is the average momentum return. Dur2 indicates the two-factor model of NMF and MKT, FF3 is the Fama-French three-factor model and FF5 is the FamaFrench five-factor model. [t] stands for the Newey-West $t$-statistics with lag 4 . The sample period is from July 2001 to June 2019

Table 9.

Explanatory power of duration factor on momentum returns

The main results of Table 9 are summarized as follows. First, the slope on the duration factor (NMF) is always positive. The estimated slope on the duration factor of WML10, WML20 and WML30 is 0.40 ( $t$-statistic of 2.79), 0.44 ( $t$-statistic of 3.52$)$ and $0.28(t$ statistic of 2.68), respectively. Second, Table 9 presents the individual models' explanatory power (measured by the explaining proportion) for the momentum strategy returns, and we find that a two-factor model of MKT and NMF shows the much higher explanatory power than other models. For example, with the WML20 portfolio, MKT and NMF have the explaining proportion of $58 \%$, whereas the explaining proportion of the FF3 and the FF5 is very low at $15 \%$ and $18 \%$, respectively. In particular, in terms of low and insignificantly estimated MKT beta, we can infer that most of the explanatory power of the two-factor model for the momentum strategy returns comes from the duration factor. Third, the risk-adjusted 
JDQS 29,1

return of the momentum strategies measured by alpha is statistically insignificant in all regressions, indicating that the duration factor explains the momentum returns well.

Consequently, the results of Table 9 imply that the duration factor is the main driving force in explaining momentum returns. This is consistent with the study of Chen and Yang (2019) which shows that momentum strategy earns a positive return in a state of a preference for the short-term future when the duration factor generates a positive return because past winners have relatively lower duration than past losers.

Finally, we compare the explanatory power of the illiquidity factor and the duration factor for the momentum strategy returns. We perform this analysis because the explanatory power of the IML_FI for the momentum returns is linked to the duration factor, as shown in Table 5 . In other words, the duration factor return is realized at a positive value following the increase in a demand for low duration stocks providing profits more on the short-term future owing to the change in time preference, and the momentum return is positively realized at the same time because of the preference for winners that have low duration, and the illiquidity factor return is also positively realized because market liquidity rises at these times. Moreover, because foreign and institutional investors are relatively more affected by the time preference risk, the relationship between the momentum and IML_FI becomes more apparent as we found in the earlier section. This implies that the relationship between the momentum and IML_FI should disappear if the duration factor is included.

To test this, we run a time-series regression with the market factor, IML_FI and duration factor as independent variables and each momentum strategy return as a dependent variable, and the regression results are tabulated in Table 10.

Table 10 shows that estimated beta on the IML_FI is not statistically significant for all momentum strategies, and the magnitude of the beta is also close to zero. In contrast, the duration factor beta of WML10, WML20 and WML30 is estimated to be high at 0.32, 0.51 and 0.31, respectively, and the betas of WML20 and WML30 are statistically significant. Thus, when the duration factor is controlled, the explanatory power of the IML_FI for the momentum returns loses its significance. As a result, the empirical results of this study support that the duration factor is the most important ingredient in explaining the momentum profit in the Korean stock market.

\section{Conclusion}

The momentum effect is one of the most puzzling phenomena in finance. Since Jegadeesh and Titman's (1993) pioneering work for the US stock market, it has been observed in other countries and not explained by the existing asset pricing models. Prior studies find that the momentum effect is observed after the IMF crisis in the Korean stock market. Given this, we attempt to understand the driving force behind the momentum effect in the Korean stock market, and specifically, we examine the ability of the illiquidity factor and duration factor to explain the momentum strategy returns.

We find that the momentum effect is observed in the Korean stock market after the post-Asian financial crisis, and the IML_FI accounts for the momentum effect to some extent. The most striking finding of this study is that the duration factor is very powerful in explaining the momentum profits. The two-factor model consisting of the market and duration factor shows a significantly higher explanatory power for the momentum effect than the FF3 and the FF5. Furthermore, after controlling for the duration factor, the explanatory power of the IML_FI on the momentum strategy 


\begin{tabular}{|c|c|c|c|c|c|c|c|c|}
\hline & \multicolumn{4}{|c|}{ Coefficients } & \multicolumn{4}{|c|}{$[t]$} \\
\hline $\begin{array}{l}\alpha \\
\beta_{\mathrm{MKT}} \\
\beta_{\mathrm{IML} \_\mathrm{FI}} \\
\beta_{\mathrm{IML} \_\mathrm{ID}} \\
\beta_{\mathrm{NMF}} \\
\text { Explaining }\end{array}$ & \begin{tabular}{r}
\multicolumn{1}{c}{ L10 } \\
-0.28 \\
1.09 \\
0.18 \\
-0.24 \\
-0.31 \\
0.82
\end{tabular} & $\begin{array}{r}\text { M80 } \\
0.17 \\
0.97 \\
0.01 \\
-0.03 \\
-0.04\end{array}$ & $\begin{array}{r}\mathrm{W} 10 \\
-0.14 \\
1.11 \\
0.33 \\
-0.19 \\
0.01\end{array}$ & $\begin{array}{c}\text { WML10 } \\
0.14 \\
0.02 \\
0.16 \\
0.05 \\
0.32\end{array}$ & $\begin{array}{r}\mathrm{L} \text { L10 } \\
-0.92 \\
17.11 \\
1.40 \\
-2.94 \\
-3.01\end{array}$ & $\begin{array}{r}\text { M80 } \\
2.94 \\
80.15 \\
0.58 \\
-1.42 \\
-1.82\end{array}$ & $\begin{array}{r}\mathrm{W} 10 \\
-0.46 \\
16.95 \\
2.42 \\
-1.75 \\
0.09\end{array}$ & $\begin{array}{c}\text { WML10 } \\
0.29 \\
0.22 \\
0.75 \\
0.31 \\
1.58\end{array}$ \\
\hline $\begin{array}{l}\alpha \\
\beta_{\mathrm{MKT}} \\
\beta_{\mathrm{IML} \_\mathrm{FI}} \\
\beta_{\mathrm{IML} \_\mathrm{ID}} \\
\beta_{\mathrm{NMF}} \\
\text { Explaining }\end{array}$ & \begin{tabular}{r}
\multicolumn{1}{c}{ L20 } \\
-0.21 \\
1.04 \\
0.19 \\
-0.08 \\
-0.35 \\
0.44
\end{tabular} & $\begin{array}{r}\mathrm{M} 60 \\
0.04 \\
0.99 \\
0.03 \\
0.00 \\
-0.06\end{array}$ & $\begin{array}{r}\mathrm{W} 20 \\
0.38 \\
1.04 \\
0.16 \\
-0.21 \\
0.16\end{array}$ & $\begin{array}{r}\text { WML20 } \\
0.59 \\
0.00 \\
-0.03 \\
-0.13 \\
0.51\end{array}$ & $\begin{array}{r}\mathrm{L} 20 \\
-0.81 \\
18.30 \\
1.76 \\
-1.09 \\
-3.51\end{array}$ & $\begin{array}{r}\mathrm{M} 60 \\
0.40 \\
44.85 \\
0.72 \\
0.10 \\
-1.89\end{array}$ & $\begin{array}{r}\mathrm{W} 20 \\
1.49 \\
16.92 \\
1.26 \\
-2.51 \\
1.44\end{array}$ & $\begin{array}{c}\text { WML20 } \\
1.37 \\
-0.05 \\
-0.14 \\
-0.95 \\
2.78\end{array}$ \\
\hline $\begin{array}{l}\alpha \\
\beta_{\mathrm{MKT}} \\
\beta_{\mathrm{IML} \_\mathrm{FI}} \\
\beta_{\mathrm{IML} \_\mathrm{ID}} \\
\beta_{\mathrm{NMF}} \\
\text { Explaining }\end{array}$ & \begin{tabular}{r}
\multicolumn{1}{c}{ L30 } \\
-0.10 \\
0.98 \\
0.11 \\
-0.01 \\
-0.25 \\
0.46
\end{tabular} & $\begin{array}{r}\text { M } 40 \\
0.02 \\
0.98 \\
0.05 \\
-0.04 \\
-0.02\end{array}$ & $\begin{array}{r}\text { W30 } \\
0.35 \\
1.08 \\
0.13 \\
-0.08 \\
0.06\end{array}$ & $\begin{array}{c}\text { WML30 } \\
0.45 \\
0.10 \\
0.02 \\
-0.08 \\
0.31\end{array}$ & $\begin{array}{r}\text { L30 } \\
-0.49 \\
22.68 \\
1.26 \\
-0.12 \\
-3.06\end{array}$ & $\begin{array}{r}\mathrm{M} 40 \\
0.23 \\
29.69 \\
0.66 \\
-1.26 \\
-0.49\end{array}$ & $\begin{array}{r}\text { W30 } \\
1.76 \\
21.28 \\
1.28 \\
-1.31 \\
0.66\end{array}$ & $\begin{array}{c}\text { WML30 } \\
1.27 \\
1.23 \\
0.13 \\
-0.64 \\
2.03\end{array}$ \\
\hline
\end{tabular}

Korean stock market

Notes: This table reports the regression results of the three momentum strategies' returns on the duration factor, market factor, IML_FI and IML_ID. $\beta_{\mathrm{MKT}}, \beta_{\mathrm{NMF}}, \beta_{\mathrm{IML}}$ FI and $\beta_{\mathrm{IML}}$ ID are the estimated betas on the market factor, duration factor, IML_FI and IML_ID, respectively. "Explaining (proportion)" means the explanatory power of a specific factor model for momentum returns and is calculated as follows:

$$
\text { Explaining }=\frac{\sum \beta_{i} E\left[f_{i}\right]}{\mathrm{E}[\mathrm{r}]},
$$

Table 10.

where $i$ indexes factors included in factor model $\mathrm{M}, E\left[f_{i}\right]$ is the mean return of factor $i, \beta_{i}$ is beta of the momentum returns to factor $i$ and $E[r]$ is the average momentum return. $[t]$ stands for the Newey-West $t$ statistics with lag 4. The sample period is from July 2001 to June 2019

Regression results of momentum returns on duration factor and illiquidity factor

returns disappears, which eventually confirms that the duration factor is the most important ingredient in explaining the performance of the momentum strategy in the Korean stock market.

Our study is different from prior works in that our study attempts to understand the driving forces behind the momentum effect, while most prior studies have only focused on the existence of the momentum effect. We attempt to discover the driving forces behind the momentum effect, a newly discovered asset pricing anomaly in the Korean stock market. Given the fact that understanding the cross section of stock returns is one of the most fundamental and important questions in finance, our work contributes to the existing literature on empirical asset pricing. In particular, our study is meaningful given the lack of literature studying on the source of momentum profit in the Korean stock market. We hope our study helps improve the understanding of researchers and practitioners on the performance of the momentum strategy. 


\section{JDQS 29,1}

\section{Notes}

1. It is hard to believe that the momentum effect is a consequence of data-mining in that momentum effect exists world-widely and across various asset classes.

2. While duration is a very important indicator in the bond market, it is not often used in the stock market because the maturity of stocks is not specified. However, some prior studies have employed duration in stock markets. For example, using accounting identities Dechow et al. (2004) calculate duration of stocks employing the same methodology with Macaulay Duration of bonds, and Van Binsbergen et al. (2012) calculate duration of individual stocks by classifying stocks into stocks paying dividends and stocks not paying dividends in a short-term future. These prior studies report that stocks with longer duration earns lower expected returns, which implies downward sloping yield curve. This has emerged as a new puzzle in the finance since it is not consistent with the theoretical results of Campbell and Cochrane (1999) and Bansal and Yaron (2004) who argue that the upward or flat slopes should be observed in the stock market. The work of Chen and Yang (2019) is conducted to explain the stock-duration puzzle in which short-duration stocks generate higher returns than long-duration stocks.

3. Though not reported, the average duration characteristics of WML10, WML20, WML30 (the differences in duration between winners and losers) are $-1.68,-1.32$, and -1.06 respectively, and all of the values are statistically significant at $1 \%$ level.

\section{Reference}

Ahn, Y.G. and Lee, J.D. (2004), "Investment strategy based on past stock returns and trading volume", Korean Journal of Financial Studies, Vol. 33 No. 1, pp. 105-137.

Albuquerque, R., Eichenbaum, M., Luo, V.X. and Rebelo, S. (2016), "Valuation risk and asset pricing", Journal of Finance, Vol. 71 No. 6, pp. 2861-2904.

Amihud, Y. (2002), "Illiquidity and stock returns: cross-section and time-series effects", Journal of Financial Markets, Vol. 5 No. 1, pp. 31-56.

Asness, C.S., Moskowitz, T.J. and Pedersen, L.H. (2013), "Value and momentum everywhere”, Journal of Finance, Vol. 68 No. 3, pp. 929-985.

Avramov, D., Cheng, S. and Hameed, A. (2016), "Time-varying liquidity and momentum profits", Journal of Financial and Quantitative Analysis, Vol. 51 No. 6.

Bansal, R. and Yaron, A. (2004), "Risks for the long run: a potential resolution of asset pricing puzzles", Journal of Finance, Vol. 59 No. 4, pp. 1481-1509.

Bansal, R., Dittmar, R.F. and Lundblad, C.T. (2005), "Consumption, dividends, and the cross section of equity returns”, Journal of Finance, Vol. 60 No. 4, pp. 1639-1672.

Barberis, N., Shleifer, A. and Vishny, R. (1998), "A model of investor sentiment”, Journal of Financial Economics, Vol. 49 No. 3, pp. 307-343.

Brooks, J., Palhares, D. and Richardson, S. (2018), "Style investing in fixed income", Journal of Portfolio Management, Vol. 44 No. 4, pp. 127-139.

Campbell, J.Y. and Cochrane, J.H. (1999), "By force of habit: a consumption-based explanation of aggregate stock market behavior”, Journal of Political Economy, Vol. 107 No. 2, pp. 205-251.

Chen, Z. and Yang, B. (2019), "In search of preference shock risks: evidence from longevity risks and momentum profits", Journal of Financial Economics, Vol. 133 No. 1, pp. 225-249.

Chordia, T., Subrahmanyam, A. and Tong, Q. (2014), "Have capital market anomalies attenuated in the recent era of high liquidity and trading activity?", Journal of Accounting and Economics, Vol. 58 No. 1, pp. 41-58.

Chui, A.C., Titman, S. and Wei, K.J. (2010), "Individualism and momentum around the world", Journal of Finance, Vol. 65 No. 1, pp. 361-392. 
Cooper, M.J., Gutierrez, R.C., Jr and Hameed, A. (2004), "Market states and momentum”, Journal of Finance, Vol. 59 No. 3, pp. 1345-1365.

Daniel, K., Hirshleifer, D. and Subrahmanyam, A. (1998), "Investor psychology and security market under-and overreactions", Journal of Finance, Vol. 53 No. 6, pp. 1839-1885.

Dechow, P.M., Sloan, R.G. and Soliman, M.T. (2004), "Implied equity duration: a new measure of equity risk", Review of Accounting Studies, Vol. 9 Nos 2/3, pp. 197-228.

Eom, Y. (2013), "Momentum profits and firm size”, Korean Journal of Financial Studies, Vol. 42 No. 5, pp. 901-927.

Fama, E.F. and French, K.R. (1993), "Common risk factors in the returns on stocks and bonds”, Journal of Financial Economics, Vol. 33 No. 1, pp. 3-56.

Fama, E.F. and French, K.R. (1996), "Multifactor explanations of asset pricing anomalies", Journal of Finance, Vol. 51 No. 1, pp. 55-84.

Fama, E.F. and French, K.R. (2012), "Size, value and momentum in international stock returns", Journal of Financial Economics, Vol. 105 No. 3, pp. 457-472.

Griffin, J.M., Ji, X. and Martin, J.S. (2003), "Momentum investing and business cycle risk: evidence from pole to pole", Journal of Finance, Vol. 58 No. 6, pp. 2515-2547.

Hofstede, G. (2001), Culture's Consequences: Comparing Values, Behaviors, Institutions and Organizations across Nations, Sage.

Hong, H. and Stein, J.C. (1999), "A unified theory of under reaction, momentum trading, and overreaction in asset markets", Journal of Finance, Vol. 54 No. 6, pp. 2143-2184.

Jang, J. (2017), "Price momentum anomaly revisited: evidence in the Korean stock market", Asian Review of Financial Research, Vol. 30 No. 3, pp. 317-359.

Jang, J., Kang, J. and Lee, C. (2012), "Liquidity risk and expected stock returns in Korea: a new approach", Asia-Pacific Journal of Financial Studies, Vol. 41 No. 6, pp. 704-738.

Jegadeesh, N. and Titman, S. (1993), "Returns to buying winners and selling losers: implications for stock market efficiency”, Journal of Finance, Vol. 48 No. 1, pp. 65-91.

Jung, J.H. and Kim, D.H. (2002), "Analyzing investment performance based on the past stock prices", Korean Journal of Financial Engineering, Working Paper.

Kang, H., Kang, J. and Kim, W. (2019), "A comparison of new factor models in the Korean stock market”, Asia-Pacific Journal of Financial Studies, Vol. 48 No. 5, pp. 593-614.

Kang, J., Kwon, K. and Park, H.J. (2014), "Momentum and foreign investors: evidence from the Korean stock market", Emerging Markets Finance and Trade, Vol. 50 No. sup5, pp. 131-147.

Kho, B.C. (2006), "Interaction of momentum returns in stock and bond markets in Korea", Korean Journal of Financial Studies, Vol. 35 No. 1, pp. 103-133.

Kim, C. and Lee, C. (2018), "Market liquidity and momentum profits: evidence from the Korean stock market", Korean Journal of Futures and Options, Vol. 26 No. 4, pp. 497-524.

Lee, C. and Jang, J. (2015), "Size, book-to-market, and momentum effects across economic states: evidence from the Korean stock market”, Korean Journal of Financial Management, Vol. 32 No. 2, pp. 201-234.

Lettau, M. and Wachter, J.A. (2007), "Why is long-horizon equity less risky? A duration-based explanation of the value premium", Journal of Finance, Vol. 62 No. 1, pp. 55-92.

Liu, L.X. and Zhang, L. (2008), "Momentum profits, factor pricing, and macroeconomic risk", Review of Financial Studies, Vol. 21 No. 6, pp. 2417-2448.

Moon, S. and Song, J. (2019), "Cross-section of expected returns based on equity duration”, Korean Journal of Futures and Options, Vol. 27 No. 3, pp. 297-327.

Novy-Marx, R. (2012), “Is momentum really momentum?”, Journal of Financial Economics, Vol. 103 No. 3, pp. 429-453. 
JDQS

29,1

Pástor, L. and Stambaugh, R.F. (2003), "Liquidity risk and expected stock returns”, Journal of Political Economy, Vol. 111 No. 3, pp. 642-685.

Rouwenhorst, K.G. (1998), "International momentum strategies", Journal of Finance, Vol. 53 No. 1, pp. 267-284.

Van Binsbergen, J., Brandt, M. and Koijen, R. (2012), "On the timing and pricing of dividends", American Economic Review, Vol. 102 No. 4, pp. 1596-1618.

Weber, M. (2018), "Cash flow duration and the term structure of equity returns”, Journal of Financial Economics, Vol. 128 No. 3, pp. 486-503.

\section{Further reading}

Fama, E.F. and French, K.R. (2015), "A five-factor asset pricing model”, Journal of Financial Economics, Vol. 116 No. 1, pp. 1-22.

\section{Corresponding author}

Changjun Lee can be contacted at: leechangjun@hufs.ac.kr

For instructions on how to order reprints of this article, please visit our website: www.emeraldgrouppublishing.com/licensing/reprints.htm

Or contact us for further details: permissions@emeraldinsight.com 